\title{
Gender-specific associations between atherogenic index of plasma and the presence and severity of acute coronary syndrome in very young adults: a hospital- based observational study
}

\author{
Gaojun Cai ${ }^{1,2+}$, Wei Liu ${ }^{1+}$, Sai Lv' ${ }^{1}$ Xu Wang ${ }^{3}$, Yonghe Guo ${ }^{1}$, Zhenxian Yan ${ }^{1}$, Yu Du ${ }^{1}$ and Yujie Zhou ${ }^{1 *}$
}

\begin{abstract}
Objective: The value of atherogenic index of plasma (AIP) as a predictive biomarker for coronary artery disease (CAD) remains controversial. In addition, whether AIP is associated with the risk of acute coronary syndrome (ACS) in very young adults has not been well established.

Methods: We consecutively collected very young adults ( $\leq 35$ years of age) undergoing coronary angiography (CAG) at Anzhen Hospital, between January 2008 and December 2017. Total of 1, 478 very young participants, including 1,059 ACS patients and 419 non-CAD subjects, were enrolled in the present study.

Results: Very young patients with ACS had higher AIP level compared with non-CAD participants $(0.35 \pm 0.30$ vs 0 . $21 \pm 0.33, P<0.001)$. According to Gensini Score (GS) and number of lesion vessel, patients were divided into four groups, respectively. With the elevated GS score and number of lesion vessels, the AIP level increased gradually ( $P_{\text {for }}$ trend all< 0.05 ). Multivariate logistic regression analyses suggested that AIP remained to be independently associated with the presence of ACS and was superior to traditional lipid profiles (for AIP, OR $=2.930,95 \% \mathrm{Cl}=1.855-4.627, P$ $<0.001$; for total cholesterol, $\mathrm{OR}=1.152,95 \% \mathrm{Cl}=1.048-1.266, P=0.003$; for triglyceride, $\mathrm{OR}=1.078,95 \% \mathrm{Cl}=0.991-$ $1.172, P=0.079$; for low-density lipoprotein cholesterol, $\mathrm{OR}=1.046,95 \% \mathrm{Cl}=1.015-1.078, P<0.001$ ), after adjustment for other traditional confounders. Moreover, the prevalence of ACS, acute myocardial infarction, unstable angina pectoris and the value of GS were also elevated as AIP quartiles increased ( $\left.P_{\text {for trend }}<0.001\right)$. Subgroup analysis based on gender revealed that AIP was only independently associated with the ACS risk in male.

Conclusions: AIP was independently associated with the presence and severity of ACS in very young patients in a gender-dependent manner, which might be superior to traditional lipid profiles.
\end{abstract}

Keywords: Acute coronary syndrome, Lipid, Atherogenic index of plasma, Young

\footnotetext{
* Correspondence: azzyj12@163.com

Gaojun Cai and Wei Liu are contributed equally to the article as the first authors.

'Department of Cardiology, 12th ward, Beijing Anzhen Hospital, Capital Medical University, Beijing Institute of Heart Lung and Blood Vessel Disease, Beijing Key Laboratory of Precision Medicine of Coronary Atherosclerotic Disease, Clinical center for coronary heart disease, Capital Medical University, Beijing 100029, China

Full list of author information is available at the end of the article
}

(c) The Author(s). 2019 Open Access This article is distributed under the terms of the Creative Commons Attribution 4.0 International License (http://creativecommons.org/licenses/by/4.0/), which permits unrestricted use, distribution, and reproduction in any medium, provided you give appropriate credit to the original author(s) and the source, provide a link to the Creative Commons license, and indicate if changes were made. The Creative Commons Public Domain Dedication waiver (http://creativecommons.org/publicdomain/zero/1.0/) applies to the data made available in this article, unless otherwise stated. 


\section{Introduction}

Coronary artery disease (CAD) remains the leading cause of morbidity and mortality worldwide [1]. With the development of modernization and changes in lifestyle, including increased consumption of meat and reduced physical exercise, the incidence of CAD was gradually increased in recent years in China [2]. According to 2017 annual report, there are about 11 million CAD patients in China, which has been the important public health problem [3]. Acute coronary syndrome (ACS), including acute myocardial infarction (AMI) and unstable angina pectoris (UAP) is the most severe type in CAD. The results of the China PEACE-Retrospective Acute Myocardial Infarction Study showed that, from 2001 to 2011, the national rates of hospital admission for STEMI increased greatly (from 3.5 per 100,000 people in 2001 , to 15.4 per 100,000 people in 2011) [4].

Dyslipidemia in traditional lipid profiles, including total cholesterol (TC), low-density lipoprotein cholesterol (LDL-C), triglyceride (TG) and high-density lipoprotein cholesterol (HDL-C) has been identified as the major risk factor for ACS. Many studies demonstrated that effectively decreasing LDL-C could significantly reduce the cardiovascular events. However, some patients with statin treatment remain having the elevated risk of cardiovascular events, that is residual risk [5].

Atherogenic index of plasma (AIP), expressed as the logistical transformation of the mole ratio of TG to HDL-C, was a significant predictor of AS and better than traditional pro-atherogenic lipid profiles [6]. Epidemiological studies suggested that AIP was significantly associated with obesity, essential hypertension $(\mathrm{EH})$, diabetic mellitus (DM) and other risk factors for CAD [7-9]. In recent years, AIP was identified the superior predictor of CAD and the cardiovascular events $[10,11]$. In a hospital-based observational study conducted in participants undergoing CAG, AIP was the most strong lipid parameter associated with CAD, with an odds ratio of 1.660 for an increase of 1-SD, after adjusting for age, gender, smoking, $\mathrm{EH}$ and DM [10]. Besides, studies suggested that AIP might be a better predictor for mortality risk among an older adult population, compared with individual cholesterol risk factors [12]. In a 10-year follow-up study, AIP was positively associated with the risk of all-cause death in elderly women with EH [11].

However, despite these associations, the value of AIP as a predictive biomarker for CAD remains controversial [13]. In addition, young patients with $\mathrm{CAD}$ exhibit a different risk factor profile from older ones [14]. Whether AIP is associated with the risk of ACS in very young patients has not been well established. In light of these considerations, we conducted the hospital-based observational study to investigate the relationship between AIP and the risk of ACS in very young adults ( $\leq 35$ years age) and hypothesized its predictive value to very young ACS was superior to traditional lipid profiles.

\section{Methods \\ Participants}

In this single-center observational study, we consecutively collected very young participants ( $\leq 35$ years of age) undergoing coronary angiography (CAG) at Anzhen Hospital, between January 2008 and December 2017.

The exclusion criteria were the following: 1) age $<18$ years old; 2) participants with incomplete lipid profiles data; 3) repeated hospitalization. Participants with severe renal insufficiency, nephrotic syndrome, myocarditis, infectious endocarditis, multiple arteritis, Kawasaki disease, or having history of percutanious coronary intervention were also excluded.

According to the exclusion criteria, total of 1,478 consecutively very young participants, including 1, 059 ACS patients and 419 non-CAD subjects, were enrolled in the present study. The flowchart outlining the study was shown in Fig. 1.

This study was complied with the Declaration of Helsinki and approved by the Institutional Ethics Committee of Beijing Anzhen Hospital. Written informed consent was not obtained from the participants, because of the data retrospectively obtained from electronic medical records.

\section{Biochemical parameter analysis}

Fasting venous blood was drawn from all participants. Data of clinical and demographic characteristics including age, gender, height, weight, vital signs, smoking and drinking status, history of $\mathrm{EH}$ and DM, were collected from electronic medical records. Laboratory parameters including TC, LDL-C, HDL-C, TG, total protein (TP), pre-albumin (PALB), blood urea nitrogen (BUN), creatinine (CR), fasting blood glucose (FBG) and glycated albumin (GA) were analyzed by automated biochemical analyzer. AIP was calculated as logarithmic transformation of the ratio of $\mathrm{TG}$ to HDL-C $\left[\log _{10}\right.$ (TG/HDL-C)].

\section{Diagnostic criteria}

ACS was diagnosed according to European Society of Cardiology guidelines in 2015 [15]. CAG was performed on all participants and assessed by two experienced cardiologists. The severity of coronary lesion was evaluated by Gensini score (GS) and number of stenotic coronary arteries [16]. Based on the value of GS, patients were classified into four quartiles. Besides, the number of lesion coronary artery was calculated by counting the major coronary vessel stenosis 


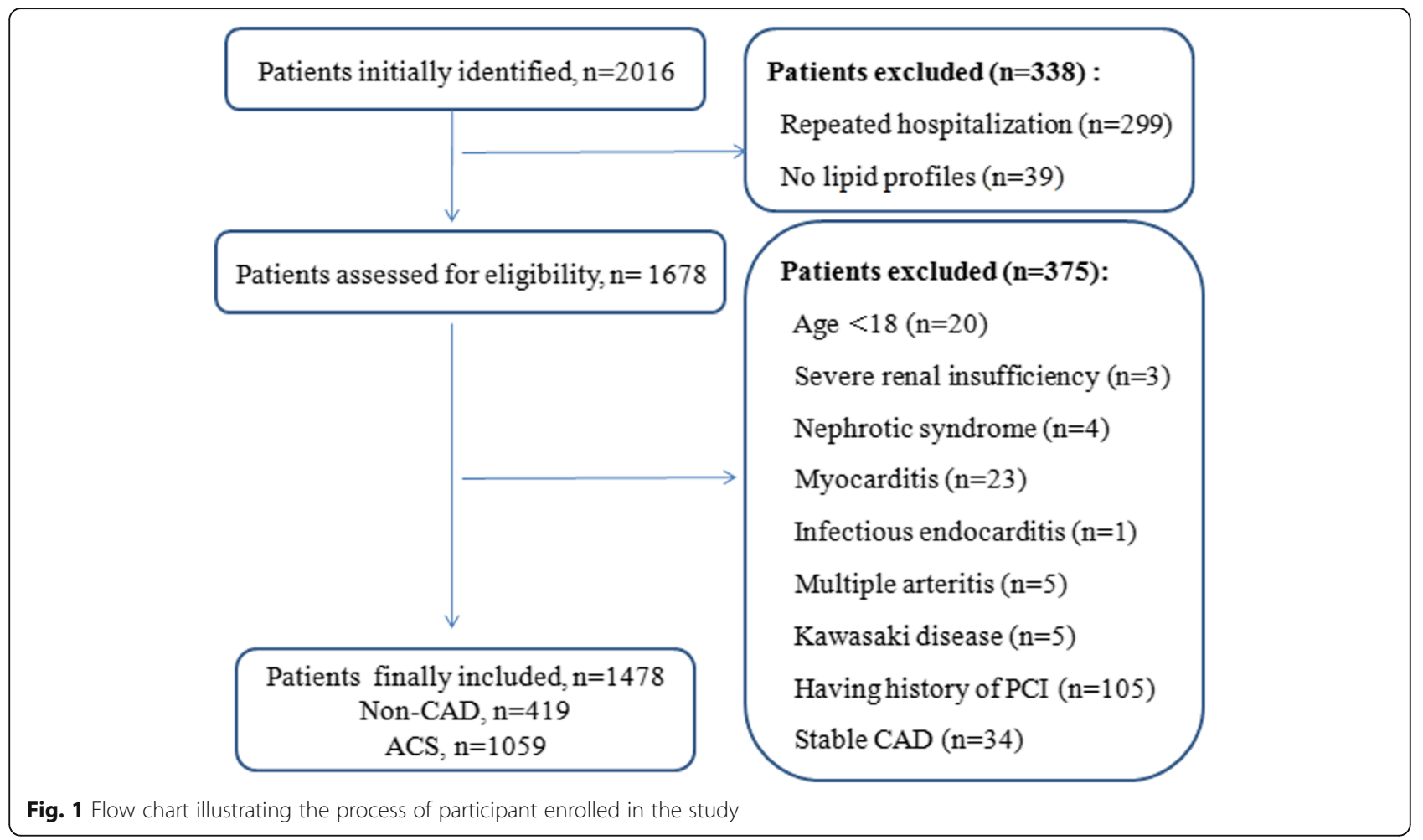

$\geq 50 \%$, which including the left main, left anterior descending, left circumflex, right coronary artery, and main branches (diameter of vessel is more than 2.0 $\mathrm{mm})$. When the stenosis in left main comes to the criteria, the number of lesion vessel was defined as two-vessel, whether or not coexists left anterior descending and/or left circumflex lesions. Patients were then classified into single-vessel, two-vessel, and three-vessel disease groups. Moreover, patients with ACS were divided into AMI and UAP groups.

The diagnostic criteria of $\mathrm{EH}$ and $\mathrm{DM}$ were described in our previously study [17]. Briefly, EH was defined as repeated systolic pressure $\geq 140 \mathrm{mmHg}$ and/or diastolic pressure $\geq 90 \mathrm{mmHg}$ at least twice, or previously diagnosed $\mathrm{EH}$. DM was defined as FGB $\geq 7.0 \mathrm{mmol} / \mathrm{l}$ and/or random glucose level $\geq 11.1 \mathrm{mmol} /$ 1, or previously diagnosed DM. Smoker and drinker were defined as regular cigarette smoking and alcohol intake, respectively.

\section{Statistic analysis}

Statistical Package for the Social Sciences (SPSS Inc., Chicago, IL, USA) 17.0 was used for statistical analysis. Continuous variables were presented as the mean \pm standard deviation (SD) and were compared using an independent samples $t$ test or one-way analysis of variance (ANOVA) if the data were normally distributed. Otherwise, the data were presented as median and interquartile range (IQR) and were compared using Mann-Whitney U test. The normality of data was evaluated by Kolmogorov-Smirnov test. Categorical variables were expressed as frequencies and percentages and were compared using a Chi-square test. The correlations between AIP and body mass index (BMI) and other lipid profiles were explored by using Pearson analysis. Multivariate logistic regression analyses, expressed as odds ratio (OR) with 95\% confidence interval $(95 \% \mathrm{CI})$, were performed to assess the association of AIP with the risk of ACS, adjusted for age, sex smoker, EH, DM (Model 1) and plus BMI (Model 2). Trend analysis was also used to detect the change trend of variables among quartiles. A value of $P<0.05$ in a two-sided test was considered statistical significantly.

\section{Results}

The baseline characteristics of involved participants

Table 1 lists the baseline characteristics of involved participants. It is not surprising that the very young patients with ACS were more likely to be male (94.9\% vs $83.83 \%, P<0.001)$. The prevalence of smoker, EH, DM and lipid-lowing treatment was significantly higher in very young ACS patients than in non-CAD subjects. Moreover, ACS patients had higher levels of WBC, RBC, PLT, FBG and GA, and lower levels of TP, PALB and BUN compared with 
Table 1 Baseline characteristics of involved participants

\begin{tabular}{|c|c|c|c|c|c|}
\hline Characteristics & Missing data n (\%) & Total $(n=1,478)$ & Non-CAD $(n=419)$ & $\operatorname{ACS}(n=1,059)$ & $P$ \\
\hline \multicolumn{6}{|l|}{ Demographic data } \\
\hline Age, years & $0(0.00)$ & $33(30-35)$ & $33(30-35)$ & $33(30-35)$ & 0.270 \\
\hline Male [n(\%)] & $0(0.00)$ & 1, $373(92.90)$ & $368(87.83)$ & $1005(94.90)$ & $<0.001$ \\
\hline Height, cm & 161 (10.89) & $172.64 \pm 6.79$ & $172.68 \pm 7.41$ & $172.62 \pm 6.51$ & 0.875 \\
\hline Weight, kg & 161 (10.89) & $82.95 \pm 15.32$ & $80.22 \pm 17.05$ & $84.12 \pm 14.37$ & $<0.001$ \\
\hline $\mathrm{BMI}, \mathrm{kg} / \mathrm{m}^{2}$ & $161(10.89)$ & $27.73 \pm 4.42$ & $26.74 \pm 4.84$ & $28.15 \pm 4.15$ & $<0.001$ \\
\hline \multicolumn{6}{|l|}{ Vital signs } \\
\hline $\mathrm{SBP}, \mathrm{mmHg}$ & $1(0.10)$ & $124.56 \pm 16.05$ & $125.12 \pm 14.48$ & $124.34 \pm 16.64$ & 0.399 \\
\hline $\mathrm{DBP}, \mathrm{mmHg}$ & $1(0.10)$ & $77.96 \pm 12.37$ & $77.95 \pm 10.97$ & $77.97 \pm 12.89$ & 0.977 \\
\hline $\mathrm{HR}$, bpm & $1(0.10)$ & $75.74 \pm 12.28$ & $75.38 \pm 12.55$ & $75.88 \pm 12.17$ & 0.480 \\
\hline \multicolumn{6}{|l|}{ Life styles } \\
\hline Smoker, n(\%) & $0(0.00)$ & $984(66.58)$ & $232(55.37)$ & $752(71.01)$ & $<0.001$ \\
\hline Drinker, n(\%) & $0(0.00)$ & $358(26.05)$ & $107(25.54)$ & $251(23.70)$ & 0.459 \\
\hline \multicolumn{6}{|l|}{ Past history } \\
\hline $\mathrm{EH}, \mathrm{n}(\%)$ & $0(0.00)$ & $491(33.22)$ & $102(24.34)$ & 389 (36.73) & $<0.001$ \\
\hline $\mathrm{DM}, \mathrm{n}(\%)$ & $0(0.00)$ & $133(9.00)$ & $22(5.25)$ & $111(10.48)$ & 0.001 \\
\hline Dyslipidaemia, n(\%) & $0(0.00)$ & $152(10.28)$ & $47(11.22)$ & 105 (9.92) & 0.449 \\
\hline Prior lipid-lowing treatment, n(\%) & $0(0.00)$ & $236(15.97)$ & $21(5.01)$ & $215(20.30)$ & $<0.001$ \\
\hline \multicolumn{6}{|l|}{ Laboratory parameters } \\
\hline $\mathrm{WBC}, \times 10^{9} / \mathrm{L}$ & $27(1.83)$ & $8.29 \pm 3.07$ & $7.13 \pm 1.88$ & $8.70 \pm 3.29$ & $<0.001$ \\
\hline $\mathrm{RBC}, \times 10^{12} / \mathrm{L}$ & $17(1.15)$ & $4.99 \pm 0.45$ & $4.98 \pm 0.51$ & $5.00 \pm 0.42$ & 0.453 \\
\hline $\mathrm{HGB}, \mathrm{g} / \mathrm{L}$ & $17(1.15)$ & $152.32 \pm 14.54$ & $152.03 \pm 16.42$ & $152.43 \pm 13.78$ & 0.629 \\
\hline $\mathrm{PLT}, \times 10^{9} / \mathrm{L}$ & $17(1.15)$ & $239.64 \pm 61.74$ & $224.70 \pm 54.48$ & $245.56 \pm 63.46$ & $<0.001$ \\
\hline $\mathrm{TP}, \mathrm{g} / \mathrm{L}$ & $16(1.08)$ & $69.65 \pm 5.60$ & $70.51 \pm 5.55$ & $69.31 \pm 5.58$ & $<0.001$ \\
\hline PALB, g/L & $27(1.83)$ & $0.28 \pm 0.06$ & $0.29 \pm 0.06$ & $0.27 \pm 0.06$ & $<0.001$ \\
\hline BUN, g/L & $4(0.27)$ & $4.723 \pm 1.59$ & $5.07 \pm 1.53$ & $4.59 \pm 1.59$ & $<0.001$ \\
\hline $\mathrm{CR}, \mathrm{mmol} / \mathrm{L}$ & $4(0.27)$ & $76.99 \pm 16.41$ & $77.42 \pm 16.98$ & $76.82 \pm 16.18$ & 0.532 \\
\hline $\mathrm{FBG}, \mathrm{mmol} / \mathrm{L}$ & $4(0.27)$ & $5.76 \pm 1.76$ & $5.34 \pm 1.21$ & $5.93 \pm 1.91$ & $<0.001$ \\
\hline $\mathrm{GA}, \%$ & $558(37.75)$ & $13.33 \pm 3.41$ & $12.77 \pm 1.77$ & $13.53 \pm 3.79$ & 0.003 \\
\hline $\mathrm{HbA} 1 \mathrm{C}, \%$ & $564(38.16)$ & $6.10 \pm 4.38$ & $6.18 \pm 8.79$ & $6.08 \pm 1.45$ & 0.788 \\
\hline Lipid profiles & $0(0.00)$ & & & & \\
\hline $\mathrm{TC}, \mathrm{mmol} / \mathrm{L}$ & & $4.58 \pm 1.35$ & $4.36 \pm 1.07$ & $4.67 \pm 1.44$ & $<0.001$ \\
\hline $\mathrm{TG}, \mathrm{mmol} / \mathrm{L}$ & & $1.82(1.26-2.78)$ & $1.58(1.07-2.40)$ & $1.95(1.33-2.89)$ & $<0.001$ \\
\hline $\mathrm{HDL}-\mathrm{C}, \mathrm{mmol} / \mathrm{L}$ & & $0.94 \pm 0.22$ & $1.03 \pm 0.25$ & $0.91 \pm 0.21$ & $<0.001$ \\
\hline $\mathrm{LDL}-\mathrm{C}, \mathrm{mmol} / \mathrm{L}$ & & $2.89 \pm 1.13$ & $2.68 \pm 0.85$ & $2.97 \pm 1.21$ & $<0.001$ \\
\hline AIP & & $0.31 \pm 0.32$ & $0.21 \pm 0.33$ & $0.35 \pm 0.30$ & $<0.001$ \\
\hline CAG characteristics & $0(0.00)$ & & & & \\
\hline One-vessel, n(\%) & & & & $519(35.12)$ & \\
\hline Two-vessel, n(\%) & & & & $244(16.51)$ & \\
\hline Three-vessel, n(\%) & & & & $192(12.99)$ & \\
\hline GS & & & & $32(14-62.75)$ & \\
\hline
\end{tabular}

$C A D$ coronary artery disease, $A C S$ acute coronary syndrome, $B M I$ body mass index, SBP systolic blood pressure, $D B P$ diastolic blood pressure, $H R$ heart rate, $D M$ diabetes mellitus, EH essential hypertension, WBC white blood cell, RBC red blood cell, HGB hemoglobin, PLT platelet, TP total protein, PALB pre-albumin, BUN blood urea nitrogen, $C R$ creatinine, FBG fasting blood glucose, GA glycated albumin, $T C$ total cholesterol, $T G$ triglyceride, HDL-C high-density lipoprotein cholesterol, LDL-C low-density lipoprotein cholesterol, AIP atherogenic index of plasma, CAG coronary angiography, GS Gensini score Bold values indicate statistical significance 
non-CAD subjects. Whereas, there were no difference in age, vital signs, the prevalence of drinker and past history of dyslipideamia between two groups. As expected, the concentrations of TC, TG and LDL-C were higher in ACS group than in non-CAD group. On the contrary, HLD-C level was significantly lower in ACS patients than that in non-CAD subjects.

\section{Correlation analysis of AIP with other variables}

As shown in Additional file 1: Table S1, in whole population, AIP was significantly positively associated with age, BMI, GA, PALB, TC, TG, LDL-C, and negatively associated with HDL-C $(P$ all $<0.05)$.

\section{Relation of AIP level and the presence and severity of ACS}

As shown in Table 1, AIP value was significantly higher in very young ACS group than in non-CAD group $(0.21 \pm 0.33$ vs $0.35 \pm 0.30, P<0.001)$. According to quartiles of GS, patients were divided into four groups (quartile 1: $\leq 12$; quartile 2 : $12-32$; quartile 3 : 32-64; quartile 4: >64). Additional file 1: Table S2 lists the clinical characteristics of ACS patients according to GS quartiles. We found that there was a significantly elevated trend of AIP as GS increased $\left(P_{\text {for trend }}=0.01\right)$. Furthermore, the correlation of AIP and number of lesion vessel was investigated. In 104
ACS patients, none of the stenosis of lesion vessels in each patient comes to $50 \%$. So, patients were classified into one-vessel $(n=519)$, two-vessel $(n=244)$ and three-vessel $(n=192)$ groups. Similarly, an elevated trend of AIP was observed as the increase of number of lesion vessels $\left(P_{\text {for }}\right.$ trend $\left.<0.001\right)$ (Additional file 1 : Table S3).

In order to assess the association of AIP with the presence and severity of ACS in very young patients, participants were further divided into four groups based on AIP quartiles (quartile 1: $<0.117$; quartile 2: $0.117-$ 0.312; quartile 3 : $0.312-0.505$; quartile $4:>0.505$ ). As shown in Table 2, the prevalence of male, EH, DM and the value of BMI, TC, TG and LDL-C were increased with the elevated AIP quartiles $(P$ for trend $<0.001)$. However, HDL-C level gradually decreased $(P$ for trend $<$ 0.001). It is not surprising that the prevalence of ACS, AMI, UAP and the value of GS were also elevated as AIP quartiles increased $(P$ for trend $<0.001)$.

Univariate and Multivariate logistic regression analyses were also used to explore the association of AIP with ACS risk (Tables 3 and 4). After adjustment for traditional confounders, we found that AIP remained to be independently associated with the presence of ACS (for ACS, OR $=2.390,95 \% \mathrm{CI}=1.855-4.627, P<$ 0.001 ; for AMI, OR $=3.872,95 \% \mathrm{CI}=2.280-6.576, P$ $<0.001$; for UAP, OR $=2.151,95 \% \mathrm{CI}=1.303-3.549, P$

Table 2 Clinical characteristics according to AIP quartiles among all participants

\begin{tabular}{|c|c|c|c|c|c|}
\hline Characteristics & Q1 $(<0.117)$ & Q2 (0.117-0.312) & Q3 (0.312-0.505) & Q4 (>0.505) & $P$ \\
\hline \multicolumn{6}{|c|}{ Clinical Characteristics } \\
\hline Age, years & $32(29-34)$ & $32(30-35)$ & $32(31-35)$ & $32(31-35)$ & $<0.001$ \\
\hline Male, n(\%) & 299 (81.03) & $352(95.14)$ & $360(97.30)$ & $362(98.10)$ & $<0.001$ \\
\hline $\mathrm{BMI}, \mathrm{kg} / \mathrm{m}^{2}$ & $25.62 \pm 4.73$ & $27.75 \pm 4.41$ & $28.72 \pm 4.18$ & $28.89 \pm 3.44$ & $<0.001$ \\
\hline Smoker, n(\%) & $176(47.70)$ & $253(68.38)$ & $279(75.41)$ & $296(80.22)$ & $<0.001$ \\
\hline $\mathrm{EH}, \mathrm{n}(\%)$ & $101(27.37)$ & $123(33.24)$ & $138(37.30)$ & 149 (40.38) & $<0.001$ \\
\hline $\mathrm{DM}, \mathrm{n}(\%)$ & $13(3.52)$ & $28(7.57)$ & $42(11.35)$ & 59 (15.99) & $<0.001$ \\
\hline \multicolumn{6}{|c|}{ Laboratory parameters } \\
\hline $\mathrm{TC}, \mathrm{mmol} / \mathrm{L}$ & $4.20 \pm 1.26$ & $4.42 \pm 1.36$ & $4.59 \pm 1.15$ & $5.11 \pm 1.46$ & $<0.001$ \\
\hline $\mathrm{TG}, \mathrm{mmol} / \mathrm{L}$ & $0.99(0.75-1.18)$ & $1.52(1.32-1.77)$ & $2.18(1.87-2.47)$ & $3.77(3.06-4.99)$ & $<0.001$ \\
\hline $\mathrm{HDL}-\mathrm{C}, \mathrm{mmol} / \mathrm{L}$ & $1.14 \pm 0.25$ & $0.95 \pm 0.17$ & $0.83 \pm 0.17$ & $0.82 \pm 0.17$ & $<0.001$ \\
\hline LDL-C, mmol/L & $2.65 \pm 1.17$ & $2.93 \pm 1.24$ & $3.02 \pm 0.99$ & $2.94 \pm 1.06$ & $<0.001$ \\
\hline \multicolumn{6}{|l|}{ CAG characteristics } \\
\hline ACS, n (\%) & $210(56.91)$ & $271(73.24)$ & $282(76.22)$ & $296(80.22)$ & $<0.001$ \\
\hline AMl, n (\%) & $106(28.73)$ & $154(41.62)$ & $169(45.68)$ & $177(47.97)$ & $<0.001$ \\
\hline UAP, n (\%) & $104(28.18)$ & $117(31.62)$ & $113(30.54)$ & $119(32.25)$ & $<0.001$ \\
\hline GS & $5(0-32)$ & $16(0-44.75)$ & $20(0-48.5)$ & $25(3-56)$ & $<0.001$ \\
\hline
\end{tabular}

ACS acute coronary syndrome, $A M I$ acute myocardial infarction, UAP unstable angina pectoris, $Q$ quartile, $B M I$ body mass index, $D M$ diabetes mellitus, $E H$ essential hypertension, $T C$ total cholesterol, TG triglyceride, HDL-C high-density lipoprotein cholesterol, LDL-C low-density lipoprotein cholesterol, AIP atherogenic index of plasma, CAG coronary angiography, GS Gensini score

Bold values indicate statistical significance 
Table 3 Univariate regression analysis of the association of ACS with variables

\begin{tabular}{llll}
\hline Variables & OR & $95 \% \mathrm{Cl}$ & $P$ \\
\hline Age & 1.043 & $1.009-1.078$ & $\mathbf{0 . 0 1 2}$ \\
Male & 2.579 & $(1.727-3.851)$ & $<\mathbf{0 . 0 0 1}$ \\
BMI & 1.079 & $1.049-1.110$ & $<\mathbf{0 . 0 0 1}$ \\
Smoker & 1.974 & $1.563-2.495$ & $<\mathbf{0 . 0 0 1}$ \\
Drinker & 0.906 & $0.698-1.176$ & 0.458 \\
EH & 1.591 & $1.240-2.043$ & $<\mathbf{0 . 0 0 1}$ \\
DM & 2.092 & $1.304-3.355$ & $\mathbf{0 . 0 0 2}$ \\
Dyslipideamia & 0.873 & $0.605-1.261$ & 0.469 \\
PALB & 0.008 & $0.001-0.052$ & $<\mathbf{0 . 0 0 1}$ \\
TC & 1.209 & $1.101-1.327$ & $<\mathbf{0 . 0 0 1}$ \\
TG & 1.211 & $1.111-1.321$ & $<\mathbf{0 . 0 0 1}$ \\
HDL-C & 0.111 & $0.066-0.186$ & $<\mathbf{0 . 0 0 1}$ \\
LDL-C & 1.299 & $1.157-1.459$ & $<\mathbf{0 . 0 0 1}$ \\
AIP & 4.707 & $3.184-6.960$ & $<\mathbf{0 . 0 0 1}$ \\
\hline ACS & &
\end{tabular}

$A C S$ acute coronary syndrome, $B M I$ body mass index, $D M$ diabetes mellitus, $E H$ essential hypertension, $P A L B$ pre-albumin, $T C$ total cholesterol, $T G$ triglyceride, $H D L-C$ high-density lipoprotein cholesterol, LDL-C low-density lipoprotein cholesterol, AIP atherogenic index of plasma, OR odds ratio, $\mathrm{Cl}$ confidence interval

Bold values indicate statistical significance

$=0.003$ ), which was superior to traditional lipid profiles. Moreover, patients with quartile 4 AIP had 1.97-fold risk for ACS (95\% CI =1.27-2.56), compared with those with quartile 1 (Fig. 2). Subgroup analysis stratified by gender was also carried out. Interestingly, the independent association of AIP with ACS risk only existed in male subgroup (Table 4).

Additionally, sensitive analysis was performed by calculating the results again when omitting participants prior receiving lipid-lowing drugs. As expected, the results were not obviously changed (data not shown).

\section{Discussion}

To our knowledge, the present study firstly evaluated the relationship between AIP and ACS risk in very young adults ( $\leq 35$ years old) in a large scale. We found that AIP was independently associated with the presence and severity of ACS in very young patients in a gender-dependent manner, which was superior to traditional lipid profiles.

In past decade, the incidence of young CAD increased greatly [18]. Numerous studies have shown significant differences in the risk factors, clinical presentation and angiographic profile between young and older patients with ACS [19]. In the present study, total of 1,478 participants were enrolled, including 419 non-CAD subjects and 1, 059 ACS patients. In our study, males were more likely to be with ACS. The prevalence of smoker, DM and EH were also significantly higher in very young ACS patients compared with non-CAD subjects.

As a surrogate of the small low-density lipoprotein particle size and needing no extra cost [20], AIP was proposed to be an economic and reliable indicator for CAD clinically. Epidemiological studies showed that the mean AIP level was varied in different populations. According to the report of Northeast China Rural Cardiovascular Health Study, the prevalence of high AIP (>0.21) was $23.1 \%$ in middle-aged subjects in the rural areas of northeast China [21]. However, the AIP level was 0.46 in Turkey population [22] and -0.1 in staff of an university in Malaysia [9]. Besides the ethnicity and region, diets and physical activity could lead to the difference in AIP in different studies [23-25]. The median level of AIP in whole population was 0.312 in our study, which was higher than that in South China and lower than Turkey population. This discrepancy might be partly interpreted by difference in age, region and ethnicity.

Evidence from epidemiological and clinical analyses showed an independent association between AIP and risk factors for cardiovascular disease. In 2018, Shen SW et al [26] suggested that AIP was linearly correlated with waist circumference and was used as a reference to estimate abdominal obesity. Besides, AIP was independently associated with CAD risk in male and multi-vessel lesson patients after adjustment for risk confounders [27].

Despite promising evidence on AIP as a novel biomarker of CAD, current data were inadequate for its use clinically. Additionally, despite very young ACS accounting for a growing proportion of sudden death in young people and the terrible influence on society and family, there were limited studies investigating the effect of AIP on the risk of ACS in very young patients. Thus, we conducted this large-scale observational study to evaluate the association of AIP with ACS risk in very young participants. Our results suggested that the very young patients with ACS had higher AIP level than non-CAD participants $(0.35 \pm$ 0.30 vs $0.21 \pm 0.33, P<0.001)$. Further, we evaluated the association of AIP with the severity of ACS in very young patients. In ACS patients, the AIP gradually increased with the elevated GS score and number of lesion vessels ( $P$ for trend all< $<0.05$ ). Multivariate logistic regression analyses suggested that AIP remained to be independently associated with the presence of ACS and was superior to traditional lipid profiles after adjustment for traditional confounders. In very young adults, AIP level might be a better predictor for ACS, and management and control of 
Table 4 Multivariate logistic regression analysis of the risk of ACS with lipid parameters on a continuous scale

\begin{tabular}{|c|c|c|c|c|c|c|c|}
\hline & \multirow{2}{*}{$\begin{array}{l}\text { Lipid } \\
\text { parameters }\end{array}$} & \multicolumn{3}{|c|}{ Model 1} & \multicolumn{3}{|c|}{ Model 2} \\
\hline & & $\overline{\mathrm{OR}}$ & $95 \% \mathrm{Cl}$ & $P$ & $\overline{\mathrm{OR}}$ & $95 \% \mathrm{Cl}$ & $P$ \\
\hline \multirow[t]{5}{*}{ Total } & $\mathrm{TC}$ & 1.183 & $1.077-1.299$ & $<0.001$ & 1.152 & $1.048-1.266$ & 0.003 \\
\hline & $\mathrm{TG}$ & 1.125 & $1.034-1.223$ & 0.006 & 1.078 & $0.991-1.172$ & 0.079 \\
\hline & $\mathrm{HDL}-\mathrm{C}$ & 0.150 & $0.088-0.259$ & $<0.001$ & 0.134 & $0.075-0.241$ & $<0.001$ \\
\hline & LDL-C & 1.269 & $1.131-1.424$ & $<0.001$ & 1.046 & $1.015-1.078$ & 0.004 \\
\hline & AIP & 3.276 & $2.159-4.969$ & $<0.001$ & 2.930 & $1.855-4.627$ & $<0.001$ \\
\hline \multirow[t]{5}{*}{ AMI } & $\mathrm{TC}$ & 1.221 & $1.093-1.365$ & $<0.001$ & 1.162 & $1.034-1.305$ & 0.012 \\
\hline & $\mathrm{TG}$ & 1.154 & $1.052-1.267$ & 0.003 & 1.096 & $0.995-1.208$ & 0.062 \\
\hline & $\mathrm{HDL}-\mathrm{C}$ & 0.124 & $0.066-0.235$ & $<0.001$ & 0.091 & $0.044-0.188$ & $<0.001$ \\
\hline & LDL-C & 1.338 & $1.166-1.536$ & $<0.001$ & 1.278 & $1.105-1.479$ & 0.001 \\
\hline & AIP & 4.284 & $2.664-6.889$ & $<0.001$ & 3.872 & $2.280-6.576$ & $<0.001$ \\
\hline \multirow[t]{5}{*}{ UAP } & $\mathrm{TC}$ & 1.158 & $1.043-1.286$ & 0.006 & 1.150 & $1.033-1.279$ & 0.010 \\
\hline & $\mathrm{TG}$ & 1.087 & $0.996-1.185$ & 0.060 & 1.064 & $0.975-1.161$ & 0.164 \\
\hline & $\mathrm{HDL}-\mathrm{C}$ & 0.181 & $0.094-0.349$ & $<0.001$ & 0.179 & $0.091-0.352$ & $<0.001$ \\
\hline & LDL-C & 1.217 & $1.074-1.378$ & 0.002 & 1.214 & $1.069-1.378$ & 0.003 \\
\hline & AIP & 2.314 & $1.443-3.711$ & $<0.001$ & 2.151 & $1.303-3.549$ & 0.003 \\
\hline \multirow[t]{5}{*}{ Male } & $\mathrm{TC}$ & 1.173 & $1.062-1.296$ & 0.002 & 1.142 & $1.032-1.264$ & 0.010 \\
\hline & TG & 1.118 & $1.027-1.218$ & 0.010 & 1.085 & $0.994-1.184$ & 0.068 \\
\hline & $\mathrm{HDL}-\mathrm{C}$ & 0.195 & $0.110-0.344$ & $<0.001$ & 0.157 & $0.085-0.291$ & $<0.001$ \\
\hline & LDL-C & 1.243 & $1.100-1.406$ & $<0.001$ & 1.218 & $1.074-1.381$ & 0.002 \\
\hline & AIP & 2.996 & $1.942-4.620$ & $<0.001$ & 2.917 & $1.817-4.685$ & $<0.001$ \\
\hline \multirow[t]{5}{*}{ Female } & $\mathrm{TC}$ & 1.221 & $1.093-1.365$ & $<0.001$ & 1.362 & $1.006-1.844$ & 0.045 \\
\hline & TG & 1.424 & $0.814-2.492$ & 0.215 & 1.084 & $0.692-1.699$ & 0.725 \\
\hline & $\mathrm{HDL}-\mathrm{C}$ & 0.014 & $0.001-0.135$ & $<0.001$ & 0.024 & $0.002-0.257$ & 0.002 \\
\hline & LDL-C & 1.471 & $1.016-2.131$ & $<0.001$ & 1.218 & $1.074-1.381$ & 0.002 \\
\hline & AIP & 8.844 & $1.605-48.734$ & 0.012 & 4.393 & $0.621-31.081$ & 0.138 \\
\hline
\end{tabular}

ACS acute coronary syndrome, $A M I$ acute myocardial infarction, $T C$ total cholesterol, $T G$ triglyceride, $H D L-C$ high-density lipoprotein cholesterol, $L D L-C$ low-density lipoprotein cholesterol, AIP atherogenic index of plasma, $O R$ odds ratio, $\mathrm{Cl}$ confidence interval

Model 1, adjusted for gender, age, smoker, EH and DM; Model 2, adjusted for confounders in model 1 plus BMl; Bold values indicate statistical significance

AIP level might be an important effect to reduce the ACS risk.

Previous studies suggested that there was a gender dependent difference in AIP and CAD [27]. In a cross-sectional study conducted among 108 Cameroonian postmenopausal women in Cameroon, AIP was found that might not be an independent factor impacting the risk of CVD after adjusting for confounders [28]. However, study conducted in China showed that AIP was a novel and independent predictive indicator for CAD in Chinese postmenopausal women [29]. In the subgroup analysis stratified by gender, we found that AIP was only independently associated with ACS risk in male, which was inconsistent with Wu TT et al [29]. However, we must realize that only 105 (7.1\%) participants enrolled in the study were female, which might influence the statistic effect. We should interpret it cautiously.

\section{Limitations}

Some limitations of this study should be considered when we interpreted the results. Firstly, the major limitation was the design of this study. The present study was a hospital-based observational study. Although the sample size was large, we could not obtain the cause-result effect, which should be verified by further cohort study. Secondly, we could not ensure the medical history data of every enrolled participant was accurate, also due to the retrospective design. However, the large-scale sample size might reduce the statistic error. Thirdly, 236 (15.97\%) very young participants receiving lipid-lowing treatment before enrolled in our study, which might affect the results. So, we carried out the sensitivity analysis by calculating the results again when omitting these participants and the results were not changed significantly, which suggested the results of the present study were robust and credible. 


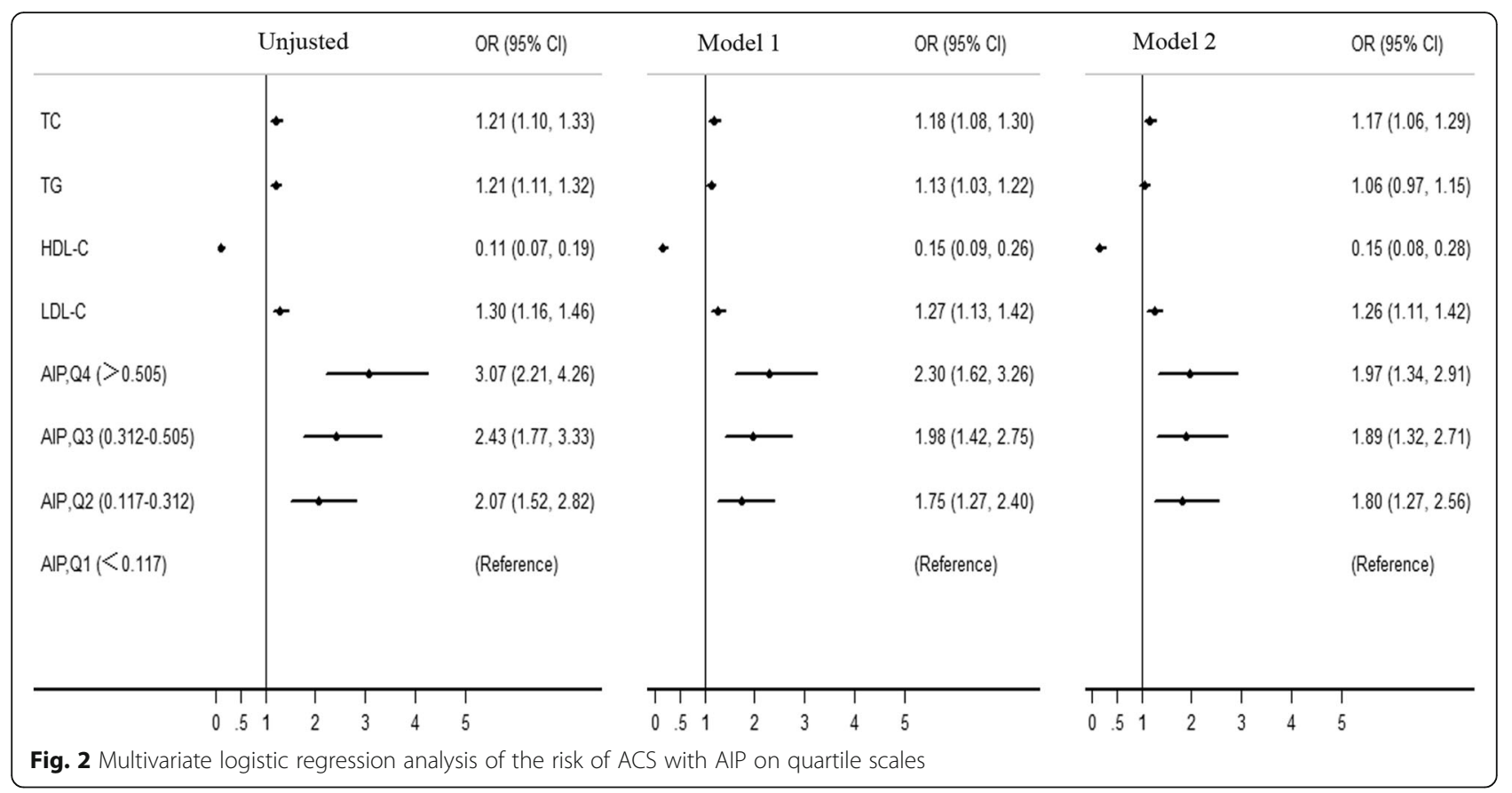

\section{Conclusions}

Despite the limitations, AIP was independently associated with the presence and severity of ACS in very young patients in a gender-dependent manner, which might be superior to traditional lipid profiles.

\section{Additional file}

Additional file 1: Table S1. Correlation analysis of AIP with other variables. Table S2. Clinical characteristics according to GS quartiles in very young adults with ACS. Table S3. Clinical characteristics according to number of lesion vessels in very young adults with ACS. (DOCX $18 \mathrm{~kb}$ )

\section{Abbreviations}

ACS: Acute coronary syndrome; AIP: Atherogenic index of plasma; CAD: Coronary artery disease; CAG: Coronary angiography; DM: Diabetes mellitus; EH: Essential hypertension; HDL-C: Highdensity lipoprotein cholesterol; LDL-C: Low-density lipoprotein cholesterol; TC: Total cholesterol; TG: Triglyceride

\section{Acknowledgements}

We thank all our colleagues at the department of Cardiology, Beijing Anzhen Hospital, Capital Medical University.

\section{Funding}

This work was supported by the grant from National Key Research and Development Program of China (2017YFC0908800); Beijing Municipal Administration of Hospitals' Ascent Plan (DFL20150601) and Mission plan (SML20180601); Beijing Municipal Health Commission "Project of Science and Technology Innovation Center" (PXM2019_026272_000006) (PXM2019_026272_000005). This study was also supported by the Jiangsu Youth Medical Talents Project (QNRC2016310).

\section{Availability of data and materials}

The datasets used and/or analyzed during the current study will be available from the corresponding author on reasonable requests after study completion.

\section{Authors' contributions}

Study conception and design: Yujie Zhou. Literature search: Gaojun Cai, Wei Liu. Data collection and analysis: Gaojun Cai, Wei Liu, Sai Lv, Xu Wang, Yonghe Guo, Zhenxian Yan, Yu Du. Data interpretation: Yujie Zhou, Gaojun Cai, Wei Liu. Writing: Gaojun Cai, Wei Liu. All authors read and approved the final manuscript.

\section{Ethics approval and consent to participate}

This study was complied with the Declaration of Helsinki and approved by the Institutional Ethics Committee of Beijing Anzhen Hospital. Written informed consent was not obtained from the participants, because of the data retrospectively obtained from electronic medical records.

\section{Consent for publication}

Not applicable.

\section{Competing interests}

The authors declare that they have no competing interests.

\section{Publisher's Note}

Springer Nature remains neutral with regard to jurisdictional claims in published maps and institutional affiliations.

\section{Author details}

'Department of Cardiology, 12th ward, Beijing Anzhen Hospital, Capital Medical University, Beijing Institute of Heart Lung and Blood Vessel Disease, Beijing Key Laboratory of Precision Medicine of Coronary Atherosclerotic Disease, Clinical center for coronary heart disease, Capital Medical University, Beijing 100029, China. ${ }^{2}$ Department of Cardiology, Wujin Hospital affiliated with Jiangsu University, Changzhou 213017, Jiangsu, China. ${ }^{3}$ Emergency \& Critical Care Center, Beijing Anzhen Hospital, Capital Medical University, Beijing 100029, China.

Received: 16 January 2019 Accepted: 2 April 2019

Published online: 13 April 2019

\section{References}

1. Gasior M, Gierlotka M, Pyka $Ł$, Zdrojewski T, Wojtyniak B, Chlebus K, Rozentryt P, Niedziela J, Jankowski P, Nessler J, Opolski G, Hoffman P, Jankowska E, Polonski L, Ponikowski P. Temporal trends in secondary prevention in myocardial infarction patients discharged with left ventricular 
systolic dysfunction in Poland. Eur J Prev Cardiol. 2018;1:2047487318770830 [PMID: 29692221].

2. Blumenthal D, Hsiao W, Blumenthal DM. Caring for coronary artery disease in China: managing modernization. JAMA Intern Med. 2016;176(4):521-3. https://doi.org/10.1001/jamainternmed.2016.0198 PMID: 26974368.

3. Chen WW, Gao RL, Liu LL, Zhu ML, Wang W, Wang YJ, et al. Report on cardiovascular diseases in China (2017, summary). Chin Circ J. 2018;33(1):1-8 [In Chinese].

4. Li J, Li X, Wang Q, Hu S, Wang Y, Masoudi FA, et al. ST-segment elevation myocardial infarction in China from 2001 to 2011 (the China PEACE retrospective acute myocardial infarction study): a retrospective analysis of hospital data. Lancet. 2015;385(9966):441-51.

5. Matsuura Y, Kanter JE, Bornfeldt KE. Highlighting residual atherosclerotic cardiovascular disease risk. Arterioscler Thromb Vasc Biol. 2019;39(1):e1-9. https://doi.org/10.1161/ATVBAHA.118.311999 [PMID: 30586334].

6. Dobiasova M, Frohlich J. The plasma parameter log (TG/HDL-C) as an atherogenic index: correlation with lipoprotein particle size and esterification rate in apob-lipoprotein-depleted plasma (FERHDL). Clin Biochem. 2001:34:583-8. https://doi.org/10.1016/S0009-9120(01)00263-6 [PMID: 11738396].

7. Zhu X, Yu L, Zhou H, Ma Q, Zhou X, Lei T, Hu J, Xu W, Yi N, Lei S. Atherogenic index of plasma is a novel and better biomarker associated with obesity: a population-based cross-sectional study in China. Lipids Health Dis. 2018;17(1):37. https://doi.org/10.1186/s12944-018-0686-8. [PMID: 29506577].

8. Song P, X L, X J, Zhang HQ, Yu CX, Guan QB, Zhao M, Zhang X Atherogenic Index of Plasma is Associated with Body Fat Level in Type 2 Diabetes Mellitus Patients. Curr Vasc Pharmacol. 2018;16(6):589-95. https:// doi.org/10.2174/1570161116666180103125456 [PMID: 29299987].

9. Bo MS, Cheah WL, Lwin S, Moe Nwe T, Win TT, Aung M. Understanding the Relationship between Atherogenic Index of Plasma and Cardiovascular Disease Risk Factors among Staff of an University in Malaysia. J Nutr Metab. 2018:7027624. https://doi.org/10.1155/2018/7027624 PMID: 30116641.

10. Cai G, Shi G, Xue S, Lu W. The atherogenic index of plasma is a strong and independent predictor for coronary artery disease in the Chinese Han population. Medicine (Baltimore). 2017;96(37):e8058. https://doi.org/10.1097/ MD.0000000000008058 [PMID: 28906400].

11. Bendzala M, Sabaka P, Caprnda M, Komornikova A, Bisahova M, Baneszova R, Petrovic D, Prosecky R, Rodrigo L, Kruzliak P, Dukat A. Atherogenic index of plasma is positively associated with the risk of all-cause death in elderly women : A 10-year follow-up. Wien Klin Wochenschr. 2017;129(21-22):7938. https://doi.org/10.1007/s00508-017-1264-1 [PMID:28913629].

12. Edwards MK, Blaha MJ, Loprinzi PD. Atherogenic Index of Plasma and Triglyceride/High-Density Lipoprotein Cholesterol Ratio Predict Mortality Risk Better Than Individual Cholesterol Risk Factors, Among an Older Adult Population. Mayo Clin Proc. 2017;92(4):680-1. https://doi.org/10.1016/j. mayocp.2016.12.018 [PMID: 28385200]

13. Nansseu JR, Hartopo AB, Arso IA, Setianto BY. Low plasma atherogenic index associated with poor prognosis in hospitalized patients with acute myocardial infarction. Acta Med Indones. 2016;48:106-13 [PMID: 27550879].

14. Wang X, Gao M, Zhou S, Wang J, Liu F, Tian F, Jin J, Ma Q, Xue X, Liu J, Liu $Y$, Chen $Y$. Trend in young coronary artery disease in China from 2010 to 2014: a retrospective study of young patients $\leq 45$. BMC Cardiovasc Disord. 2017;17(1):18. https://doi.org/10.1186/s12872-016-0458-1 [PMID: 28061763].

15. Roffi M, Patrono C, Collet JP, Mueller C, Valgimigli M, Andreotti F, Bax JJ, Borger MA, Brotons C, Chen DP, Gencer B, Hasenfuss G, Kjeldsen K, Lancellotti P, Landmesser U, Mehili J, Mukherjee D, Storey RF, Windecker S, ESC Scientific Document Group. 2015 ESC guidelines for the management of acute coronary syndromes in patients presenting without persistent STsegment elevation: task force for the Management of Acute Coronary Syndromes in patients presenting without persistent ST-segment elevation of the European Society of Cardiology (ESC). Eur Heart J. 2016;37(3):267-315. https://doi.org/10.1093/eurheartj/ehv320 [PMID: 26320110$].$

16. Gensini GG. A more meaningful scoring system for determining the severity of coronary heart disease. Am J Cardiol. 1983;51(3):606 [PMID: 6823874].

17. Cai G, Zhang B, Ma C, Shi G, Weng W, Xue S. Associations of rs3744841 and re3744843 polymorphisms in endothelial lipase gene with risk of coronary artery disease and lipid levels in a Chinese population. PLoS One. 2016;11(9): e0162727. https://doi.org/10.1371/journal.pone.0162727 [PMID: 27612170].

18. Arora S, Stouffer GAR, Kucharska-Newton A, Qamar A, Vaduganathan M, Pandey A, Porterfield DS, Blankstein R, Rosamond WD, Bhatt D, Caughey
MC. Twenty Year Trends and Sex Differences in Young Adults Hospitalized with Acute Myocardial Infarction: The ARIC Community Surveillance Study. Circulation. 2018 Nov 11. https://doi.org/10.1161/CIRCULATIONAHA.118. 037137 [PMID:30586725].

19. Hosseini SK, Soleimani A, Salarifar M, Pourhoseini H, Nematipoor E, Abbasi SH, Abbasi A. Demographics and angiographic findings in patients under 35 years of age with acute STElevation myocardial infarction. J Tehran Heart Cent. 2011;6(2):62-7 [PMID: 23074607].

20. Frohlich J, Dobiásová M. Fractional esterification rate of cholesterol and triglycerides to HDL-cholesterol are powerful predictors of positive findings on coronary angiography. Clin Chem. 2003;49(11):1873-80 [PMID: 14578319].

21. Chang Y, Li Y, Guo X, Dai D, Sun Y. The Association of Ideal Cardiovascular Health and Atherogenic Index of Plasma in Rural Population: A CrossSectional Study from Northeast China. Int J Environ Res Public Health. 2016; 13(10) [PMID: 27775583].

22. Kalelioğlu T, Ünalan P, Kök B, Sözen Ş, Yüksel Ö, Akkuş M, Cihnioğlu R, Karamustafalıoğlu N. Atherogenic index of plasma as a cardiovascular risk marker in manic, depressive, and euthymic stages of bipolar disorder. Turk Kardiyol Dern Ars. 2018;46(1):32-8. https://doi.org/10.5543/tkda.2017.23350 [PMID: 29339689].

23. Golzari MH, Javanbakht MH, Ghaedi E, Mohammadi H, Djalali M. Effect of Eicosapentaenoic acid (EPA) supplementation on cardiovascular markers in patients with type 2 diabetes mellitus: a randomized, double-blind, placebocontrolled trial. Diabetes Metab Syndr. 2018;12(3):411-5. https://doi.org/10. 1016/j.dsx.2018.03.003 [PMID: 29588138].

24. Shen S, Qi H, He X, Lu Y, Yang C, Li F, Wang L, Qiang D, Shui K, Zhou L, Weng $X$, Shen Z, Wu L. Aerobic exercise for a duration of $90 \mathrm{~min}$ or longer per week may reduce the atherogenic index of plasma. Sci Rep. 2018;8(1): 1730. https://doi.org/10.1038/s41598-018-20201-x [PMID: 29379137].

25. Edwards MK, Loprinzi PD. Physical activity and diet on atherogenic index of plasma among adults in the United States: mediation considerations by central adiposity. Eur J Clin Nutr. 2018;72(6):826-31. https://doi.org/10.1038/ s41430-017-0066-x [PMID: 29321685].

26. Shen SW, Lu Y, Li F, Yang CJ, Feng YB, Li HW, Yao WF, Shen ZH. Atherogenic index of plasma is an effective index for estimating abdominal obesity. Lipids Health Dis. 2018;17(1):11. https://doi.org/10.1186/s12944-0180656-1 [PMID: 29334966].

27. Ni W, Zhou Z, Liu T, Wang H, Deng J, Liu X, Xing G. Gender-and lesion number-dependent difference in "atherogenic index of plasma" in Chinese people with coronary heart disease. Sci Rep. 2017;7(1):13207. https://doi.org/ 10.1038/s41598-017-13267-6 [PMID: 29038593].

28. Nansseu JR, Moor VJ, Nouaga ME, et al. Atherogenic index of plasma and risk of cardiovascular disease among Cameroonian postmenopausal women. Lipids Health Dis. 2016;15:49 [PMID: 26957313].

29. Wu TT, Gao Y, Zheng YY, Ma YT, Xie X. Atherogenic index of plasma (AIP): a novel predictive indicator for the coronary artery disease in postmenopausal women. Lipids Health Dis. 2018;17(1):197. https://doi.org/ 10.1186/s12944-018-0828-Z [PMID: 30134981].

Ready to submit your research? Choose BMC and benefit from:

- fast, convenient online submission

- thorough peer review by experienced researchers in your field

- rapid publication on acceptance

- support for research data, including large and complex data types

- gold Open Access which fosters wider collaboration and increased citations

- maximum visibility for your research: over $100 \mathrm{M}$ website views per year

At $\mathrm{BMC}$, research is always in progress.

Learn more biomedcentral.com/submission 